\title{
A COUNTEREXAMPLE IN THE FACTORIZATION OF BANACH SPACE OPERATORS
}

\author{
RICHARD BOULDIN
}

\begin{abstract}
A counterexample is given which completes the Banach space generalization of a theorem of R. G. Douglas concerning the factorization of Hilbert space operators.
\end{abstract}

In [1] R. G. Douglas proves the equivalence of three conditions related to factoring a Hilbert space operator. In [2] Mary Embry determines all but one of the possible implications among those three conditions interpreted for operators on a Banach space. This short note gives a counterexample to show that the one remaining possible implication does not hold.

In the notation of [4] define $A$ and $B$ on $\left(c_{0}\right)$ by $A e_{k}=0$ for $k \neq 1$ and $A e_{1}=y=\left(2^{-1}, 2^{-2}, \ldots\right)$ and $B\left(x_{1}, x_{2}, \ldots\right)=\left(2^{-1} x_{1}, 2^{-2} x_{2}, \ldots\right)$. Recall $\left(c_{0}\right)^{\prime}=l^{1}$ and $\left(l^{1}\right)^{\prime}=l^{\infty}$. The straightforward proof of the next lemma is omitted.

LEMMA. The dual operator $B^{\prime \prime}$ on $l^{\infty}$ maps $\left(f_{1}, f_{2}, \ldots\right)$ to $\left(2^{-1} f_{1}, 2^{-2} f_{2}, \ldots\right)$ and the images of $B$ and $B^{\prime \prime}$ are $\left\{\left(x_{1}, x_{2}, \ldots\right) \in\left(c_{0}\right): \lim 2^{n} x_{n}=0\right\}$ and $\left\{\left(h_{1}, h_{2}, \ldots\right) \in l^{\infty}: \sup \left|2^{n} h_{n}\right|<\infty\right\}$, respectively. The operator $A^{\prime \prime}$ on $l^{\infty}$ is defined by $A^{\prime \prime}\left(g_{1}, g_{2}, \ldots\right)=g_{1} h$, where $h=\left(2^{-1}, 2^{-2}, \ldots\right)$ and the images of $A$ and $A^{\prime \prime}$ are $\operatorname{span}\{y\}$ and $\operatorname{span}\{h\}$, respectively.

THEOREM. Condition (i) below holds but (ii) does not hold:

(i) for some $c \geqslant 0,\left\|A^{\prime} f\right\| \leqslant c\left\|B^{\prime} f\right\|$ for all $f \in l^{1}$;

(ii) the image of $B$ contains the image of $A-i . e . B\left(c_{0}\right) \supset A\left(c_{0}\right)$.

Proof. From the Lemma it follows that $A^{\prime \prime} l^{\infty} \subset B^{\prime \prime} l^{\infty}$ and $A\left(c_{0}\right) \not \subset B\left(c_{0}\right)$. Theorem 1 of [2] implies that (i) above holds.

This counterexample fills a gap in [3] showing that the converse to Theorem 1 of [3] does not hold.

\section{REFERENCES}

[1] R. G. Douglas, On majorization, factorization and range inclusion of operators in Hilbert space, Proc. Amer. Math. Soc. 17 (1966), 413-416.

[2] Mary Embry, Factorization of operators on Banach space, Proc. Amer. Math. Soc. 38 (1973), 587-590.

[3] Robin Harte, Berberian-Quigley and the ghost of a spectral mapping theorem, Proc. Roy. Irish Acad. (to appear).

[4] A. E. Taylor, Introduction to functional analysis, Wiley, New York, 1963.

Department of Mathematics, University of Georgia, Athens, Georgia 30602

Received by the editors June 13, 1977.

AMS (MOS) subject classifications (1970). Primary 47A99. 